\title{
The TRPC2 channel forms protein-protein interactions with Homer and RTP in the rat vomeronasal organ
}

\author{
Thomas G Mast1,2, Jessica H Brann1,2,4 and Debra A Fadoo**1,2,3
}

\begin{abstract}
Background: The signal transduction cascade operational in the vomeronasal organ (VNO) of the olfactory system detects odorants important for prey localization, mating, and social recognition. While the protein machinery transducing these external cues has been individually well characterized, little attention has been paid to the role of protein-protein interactions among these molecules. Development of an in vitro expression system for the transient receptor potential 2 channel (TRPC2), which establishes the first electrical signal in the pheromone transduction pathway, led to the discovery of two protein partners that couple with the channel in the native VNO.

Results: Homer family proteins were expressed in both male and female adult VNO, particularly Homer 1b/c and Homer 3. In addition to this family of scaffolding proteins, the chaperones receptor transporting protein 1 (RTP1) and receptor expression enhancing protein 1 (REEP1) were also expressed. RTP1 was localized broadly across the VNO sensory epithelium, goblet cells, and the soft palate. Both Homer and RTP1 formed protein-protein interactions with TRPC2 in native reciprocal pull-down assays and RTP1 increased surface expression of TRPC2 in in vitro assays. The RTP1-dependent TRPC2 surface expression was paralleled with an increase in ATP-stimulated whole-cell current in an in vitro patch-clamp electrophysiological assay.

Conclusions: TRPC2 expression and channel activity is regulated by chaperone- and scaffolding-associated proteins, which could modulate the transduction of chemosignals. The developed in vitro expression system, as described here, will be advantageous for detailed investigations into TRPC2 channel activity and cell signalling, for a channel protein that was traditionally difficult to physiologically assess.
\end{abstract}

\section{Background}

The mammalian accessory olfactory system (AOS) functions as a detector for chemical signals (chemosignals) concerning social organization and conspecific reproductive status $[1,2]$. The vomeronasal organ $(\mathrm{VNO})$ is the primary sensory organ for the AOS. In rodents, the VNO is an encapsulated neuroepithelium containing a lumen and is able to aspirate fluids via a vascular pump [3,4]. Vomeronasal sensory neurons (VSN) express vomeronasal receptors (VRs) belonging to one of the two families of Gprotein coupled receptors (GPCRs) specific to the VNO, the V1Rs and V2Rs [5-7]. Upon binding of a chemosignal, V1Rs and V2Rs activate the G-proteins, $\mathrm{G \alpha}_{\mathrm{i} 2}$ and $\mathrm{G \alpha}_{\mathrm{o}}$,

* Correspondence: dfadool@bio.fsu.edu

1 Department of Biological Science, The Florida State University, Tallahassee, FL, 32306, USA

Full list of author information is available at the end of the article respectively [1]. G-protein activation can ultimately result in a non-specific cation current through the canonical transient receptor potential channel type 2 (TRPC2) [8-10].

VNO function is dependent upon TRPC2 [11-13]. Adaptor proteins scaffold TRPC to proteins such as inositol 1,4,5-trisphosphate receptor type $3\left(\mathrm{IP}_{3} \mathrm{R} 3\right)$ [14-16]. In the invertebrate retina TRP is in a scaffold-mediated complex whereby deletion of the scaffold leads to complex degradation and altered light responses [17]. The TRP channel and $\mathrm{IP}_{3}$ receptor are co-localized in VSN microvilli [18] whereby peptide disruption of the proteinprotein interaction between them inhibits chemosignalinduced currents [14].

Homers are adaptor proteins that bind to proline-rich sequences on proteins associated with calcium signalling 
[19]. Long Homer isoforms (1b/c, 2a/b, 3) contain, whereby the immediate-early gene encoded short isoform (1a) lacks, a coiled-coil motif that mediates multimerization $[19,20]$. Homers alter the function and distribution of metabotropic glutamate receptors (mGluRs) [20-22].

TRPC2 clones have poor surface expression in vitro and may require a chaperone for proper formation [23,24]. Receptor transporting protein 1 (RTP1) and receptor expression enhancing protein 1 (REEP1) are putative transmembrane protein chaperones expressed in the main olfactory system, which target olfactory GPCRs to the membrane and form protein-protein interactions with olfactory GPCRs in vitro [25]. RTP1 and REEP1 mRNAs are expressed in the mouse VNO, but as of yet, neither protein has been reported in VSNs, and have not been proposed to have any functional interactions with vomeronasal GPCRs [25].

Given the role of TRPC2 in chemosignal detection, the interactions of TRPC2 with adaptor proteins in other sensory systems, and chaperone mRNA expression in the VNO, we sought to test the hypothesis that TRPC2 forms protein-protein associations with partners that could alter channel function or localization. Specifically, we sought to identify interactions between TRPC2 and Homer family members and interactions between TRPC2 and RTP1 or REEP1. First, we demonstrate VNO protein expression of RTP1, Homer, and TRPC2. Next we describe novel, in vivo, interactions between TRPC2 and Homer 1b/c as well as TRPC2 and RTP1. Lastly, we demonstrate a physiological role for the interaction between RTP1 and TRPC2; in vitro co-expression of RTP1 with TRPC2 leads to increased cell-surface expression of functional TRPC2.

\section{Results}

Homer, RTP1, and REEP1 are Expressed in the Vomeronasal Organ

TRPC2 forms a protein-protein interaction with $\mathrm{IP}_{3} \mathrm{R} 3$ in rat VSNs [18] and a peptide blocker of this interaction functionally reduces odor-activated currents [14]. We therefore questioned whether adaptor proteins might moderate the scaffold complex. Rat VNO tissue was screened with an antiserum that recognized all homer isoforms (Pan-Homer). Pan-Homer antiserum was observed to label proteins at the predicted molecular weight via SDS-PAGE followed by Western analysis on NP40-solubilized tissue extracts from the hippocampus $(\mathrm{H})$, cerebellum $(\mathrm{Ce})$, cerebral hemisphere $(\mathrm{CH})$, olfactory bulb (OB), and vomeronasal organ (VNO) (Fig. 1A). Only long forms $\left(M_{r}=45 \mathrm{kDa}\right)$ were detected using the panHomer antiserum, presumably because the short form of Homer ( $\mathrm{H} 1 \mathrm{a})$ is a transient product of an activity-dependent immediate early gene [20], making detection difficult. The commercial pan-Homer antiserum (Fig. 1A), and not the investigator-generated antisera (Fig. 1B-E) (see methods), produced a non-selective band at $50 \mathrm{kDa}$, and therefore was not utilized in subsequent biochemical analyses.

Isoform-specific antisera were then utilized to further probe which Homer isoforms were predominantly found in the VNO. Homer $1 \mathrm{~b} / \mathrm{c}$ and Homer 3 were expressed in all neural tissues tested including the $\mathrm{OB}$ and the $\mathrm{VNO}$ (Figs. 1B and 1E). Repetition of SDS-PAGE and Western analysis using the same tissue extracts as in Fig. 1B resulted in no immunoreactive labelling with preimmune serum used to generate the homer $1 \mathrm{~b} / \mathrm{c}$ antiserum (Fig. $1 C)$. Homer 2 was weakly detected in the VNO, but was found in the $\mathrm{OB}$, as well as other brain regions tested (Fig. 1D). In our previous studies we have noted sexual dimorphism in the VNO [26,27], therefore, male and female VNO lysates were separately probed with Homer antisera. An appreciable sex difference was not consistently detected (Figs. 1A-E). Equal protein loading was confirmed for all Western blots by stripping the blot and then re-probing for actin immunoreactivity (i.e. Additional File 1, Fig. S1).

RTP1 and REEP1 mRNAs have only been demonstrated in the mouse [25], therefore rat VNO cDNA was screened using gene-specific primers and reverse-transcriptase PCR (RT-PCR) for chaperone expression. RTP1 and REEP1 expression in the rat VNO is reported in Fig. $1 F$. Each $\mathrm{RT}$-PCR reaction produced a single band and the identity of the band was confirmed by sequencing. An additional screening of RTP1 in the mouse main olfactory epithelium was also performed across various postnatal stages as reported in Additional File 1, Fig. S1.

Since RTP1 cellular localization has not been previously explored in the olfactory system, the determination of the cells or cellular processes that express RTP1 was made using immunoctyochemistry (ICC). Coronal sections of the rat nasal cavity containing both the vomeronasal and the main olfactory epithelium (MOE) were incubated with an antiserum for RTP1 (Fig. 2). Using an avidin-peroxidase chromagen method, putative RTP1 immunoreactivity was evident in the rat MOE cilia (osn; Fig. 2A), VNO microvilli (vsn; Fig. 2B), goblet cells (gob; Fig. 2B), and the soft palate (sp; Fig. 2B). Higher resolution micrographs of the MOE cilia and VNO microvilli can be seen in Figs. 2C and 2E, respectively. RTP1 immunoreactivity was absent from all other structures including the respiratory epithelium (res; Fig. 2D) and from the VNO microvilli that were processed without primary antiserum (Fig. 2F). To determine whether the labelling of RTP1 might overlap with previous TRPC2 microvillar localization reported by our laboratory and others $[8,18]$ we used dual-colored ICC with fluorescently-tagged secondary antisera to test for co-localization of TRPC2 and RTP1. As shown in Figs. 2G-I, the signals for the two pro- 


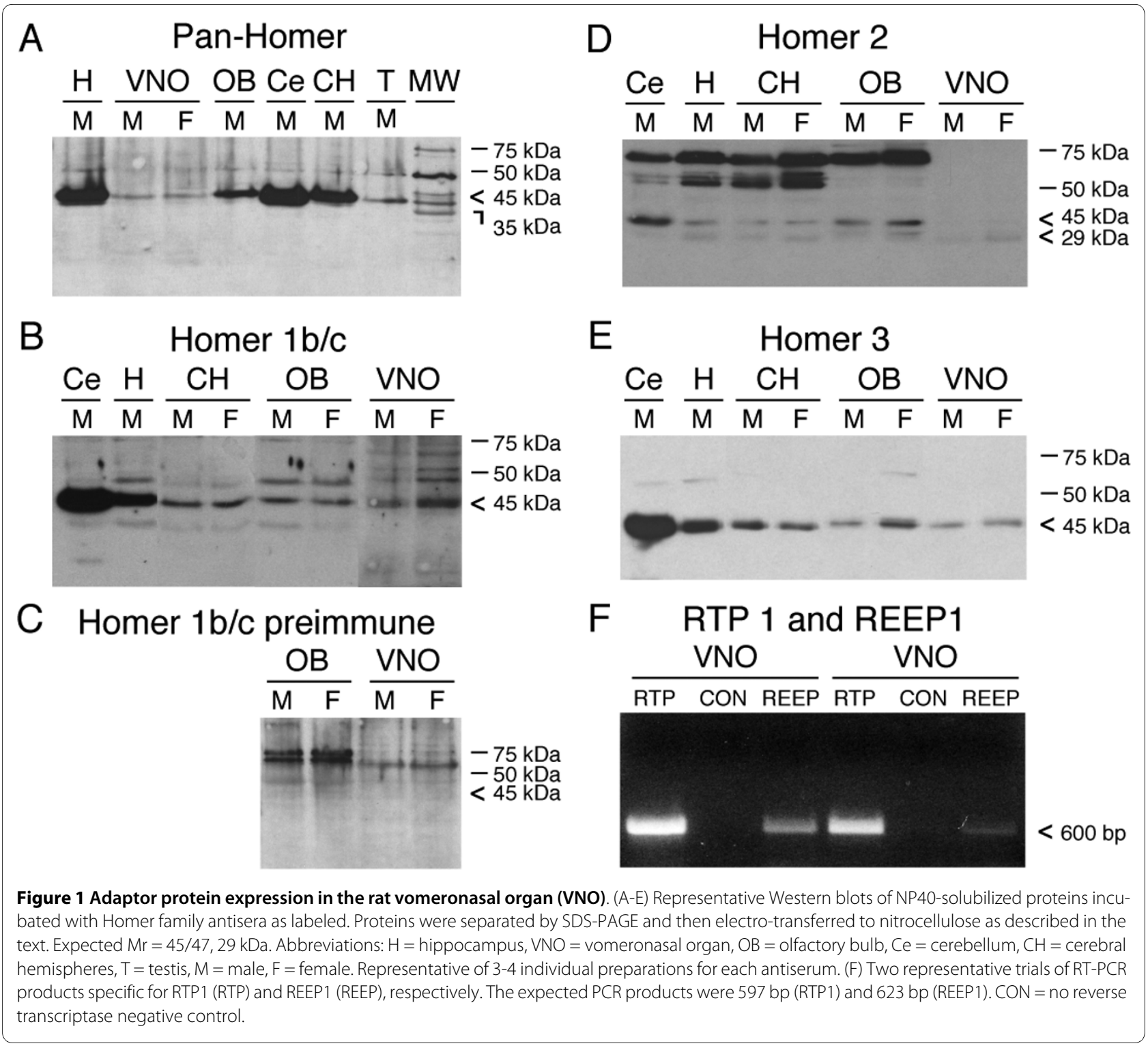

teins extensively overlap at the microvilli (m) as evidenced in the merged image overlay (Fig. 2I). Omission of primary antisera eliminated the fluorescent signal in each condition tested (Figs. 2J-L). As an additional control for RTP1 antiserum specificity, human embryonic kidney 293 (HEK293) cells were transfected with an RTP1 expression vector and then processed under non-permeabilizing conditions for RTP1 immunoreactivity. Preincubating the cells with proteinase $\mathrm{K}$ abolished the RTP1 immunoreactivity (Additional File 1, Fig. S1B, C).

\section{Homer and RTP1 form protein-protein interaction with TRPC2}

Previous in vitro data have demonstrated that TRPC 2 and Homer 1 form a protein-protein interaction [16]. Our discovered co-localization of TRPC2 and RTP1 suggests that these proteins may also bind in vivo. To test the rigor of potential protein-protein interactions, reciprocal coimmunoprecipitations were performed in native rat $\mathrm{VNO}$ lysates (Fig. 3). TRPC2 was clearly immunoprecipitated with both Homer 1b/c (Figs. 3C and 3D) and RTP1 (Figs. $3 \mathrm{E}$ and $3 \mathrm{~F})$. Interestingly, Homer $1 \mathrm{~b} / \mathrm{c}$ could co-immunoprecipitate with both $\mathrm{IP}_{3} \mathrm{R} 3$ (Fig. 3A and $3 \mathrm{~B}$ ) and TRPC2. Additional negative controls using rabbit sera as the first source for immunoglobulins failed to produce bands at the expected molecular weight (Additional File 1, Fig. S1D). Protein interactions with REEP1 could not be investigated due a lack of available antiserum.

\section{TRPC2 transfection efficiency in a heterologous expression} system

Due to the reported increased surface expression of olfactory receptors by the chaperone RTP1 [25] and our dis- 

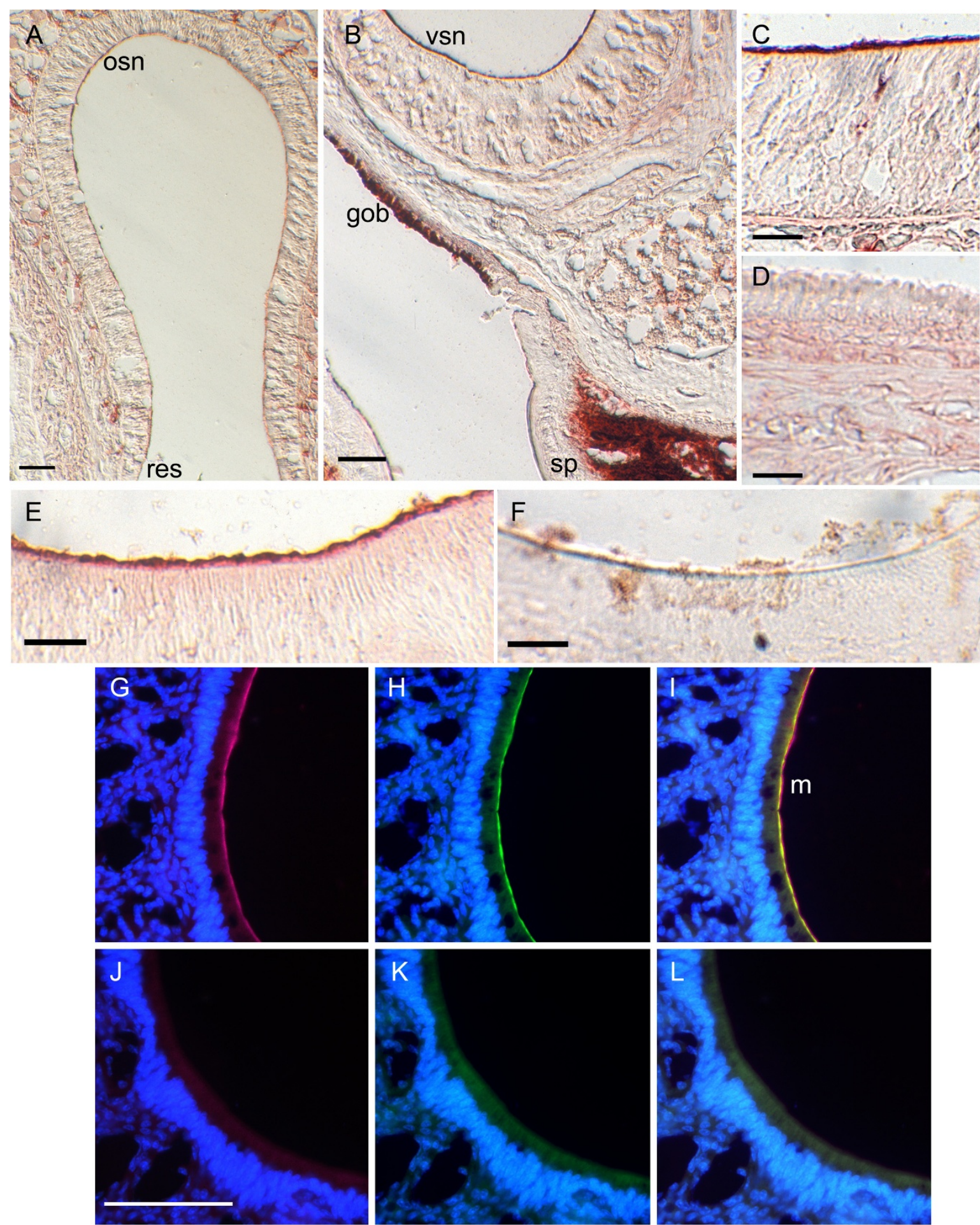

Figure 2 TRPC2/RTP1 co-localization in the rat nasal cavity. Sixteen micron coronal sections were processed for aRTP1 immunocytochemistry using an avidin-peroxidase chromagen method (A-F) or dual-colored immunocytochemistry with fluorescent secondary antisera (G-L). Low-power magnification of the (A) main olfactory epithelium (MOE) and (B) vomeronasal epithelium. osn = olfactory sensory neuron, res = respiratory epithelium, $\mathrm{vsn}=$ vomeronasal sensory neuron, gob = goblet cells, sp = soft palate. Higher-power magnification reveals aRTP1 labelling in the cilia layer of the $\mathrm{MOE}$ (inset $\mathrm{C}$ ) and microvilli layer of the $\mathrm{VNO}$ (inset $\mathrm{E}$ ) but absence of label in the respiratory cilia (inset D). Control VNO section with omission of primary antiserum (F). Higher-power magnification of the VNO (G-L), aRTP1 (G), aTRPC2 (H), merged image (I). Control sequential sections to that of G-I with omission of the primary antisera (J-L). Scale bar $25 \mu \mathrm{m}$ (C-F) or $100 \mu \mathrm{m}$ (A, B, G-L). Scale bar in J is the same for G-L. Italicized lettering in boxes is linked to enlarged image sub-panel. $m=$ microvillar layer. 


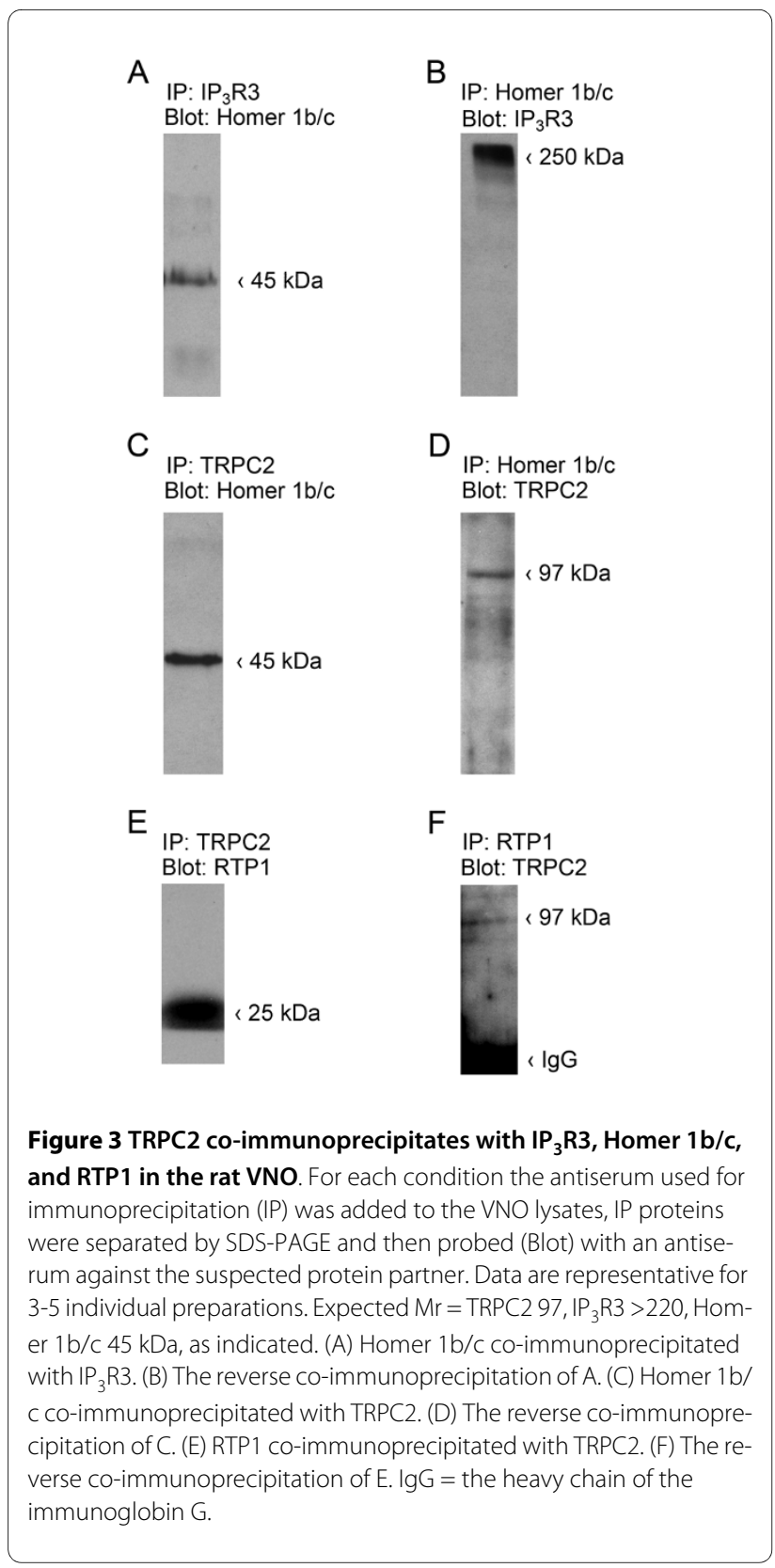

covery of its interaction and cellular co-localization with TRPC2, we hypothesized that the chaperone would increase the surface expression of TRPC2. To test this, TRPC2 was expressed with or without either RTP1 or REEP1 in HEK293 cells. Transfected cells were incubated with an antiserum for the myc-epitope tag on the plasmid-encoded TRPC2 and then visualized using a speciesspecific FITC-conjugated secondary antiserum. A representative field of view used to calculate the transfection efficiency for various transfection conditions is shown in Fig. 4. The ratio of fluorescent cells (left column, Figs. 4A, C, E, and 4G) over that of all cells (right column, Figs. 4B, $\mathrm{D}, \mathrm{F}$, and $4 \mathrm{H}$; DAPI nuclear stain) was used to calculate
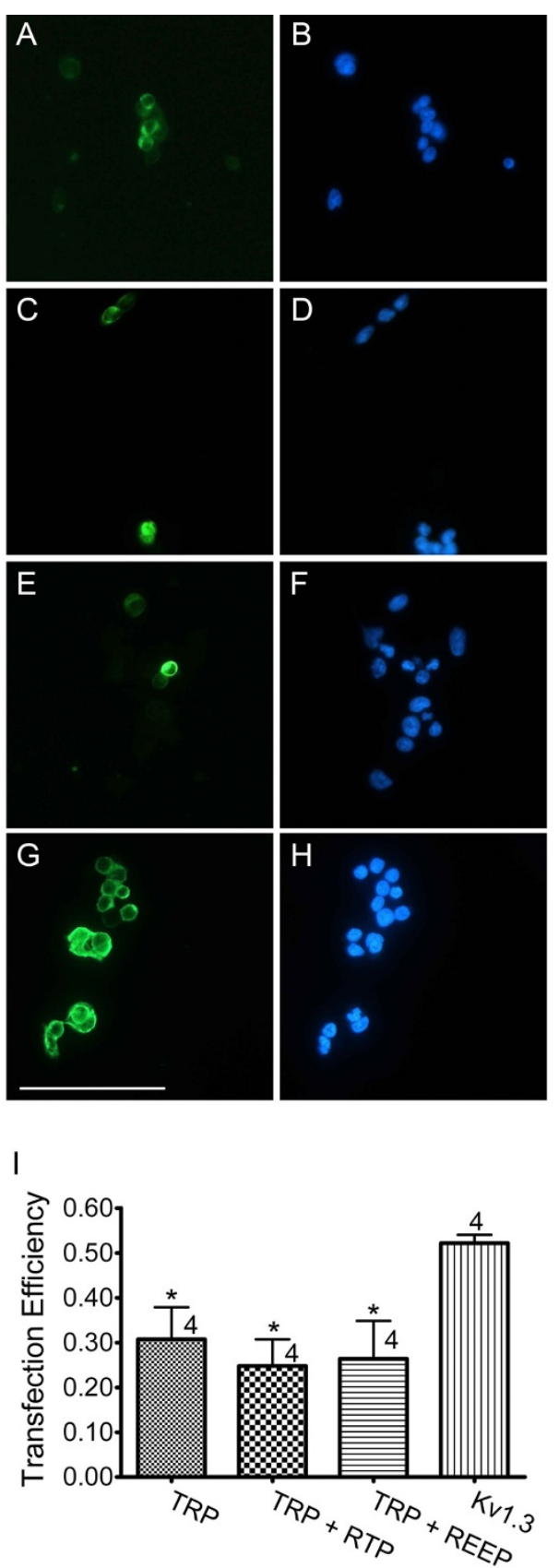

Transfection Condition

Figure 4 TRPC2 transfection efficiency in HEK293 cells. (A-H) Representative micrographs of cells grown on glass-coverslips, transfected as in text, incubated with an antiserum to the c-myc epitope and labeled with FITC-conjugated secondary antiserum. (A, C, E, and G) Representative fields of view for antiserum specific fluorescence (green). $(B, D, F$, and $H)$ The same fields of view as in images $B, D, F$, and $H$ with DAPI nuclear stain (blue). Note the low percentage of cells transfected in (A, B) TRPC2, (C, D) TRPC2 + RTP1, (E, F) TRPC2 + REEP1, as compared to $(G, H) K v 1.3$. The scale bar in $G$ is $100 \mu m$. (I) Histogram plot of the ratio of transfected cells. The number of quantified transfections are noted. ${ }^{*}=$ denotes a mean pixel density significantly different from Kv1.3 transfection; one-way ANOVA followed by a snk post-hoc test ( $p$ $\leq 0.05)$ 

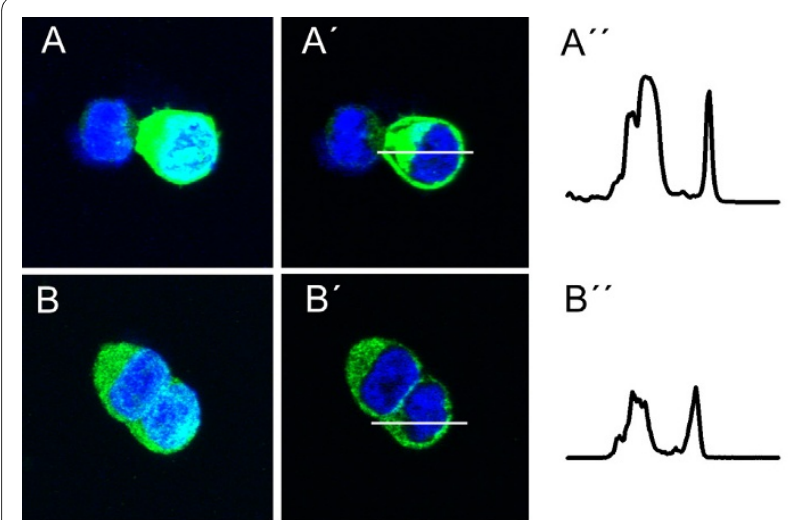

$\mathrm{B}^{\prime \prime}$
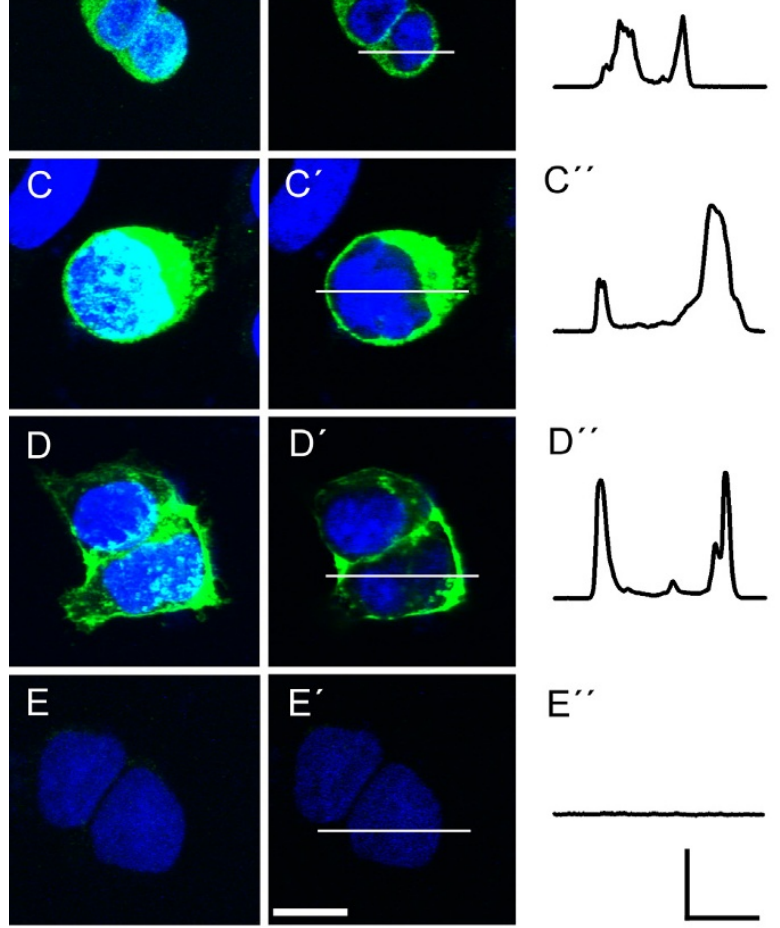

Figure 5 Subcellular localization of TRPC2 in HEK293 cells. (A-E) Representative two-photon confocal micrographs of cells grown, transfected, and immunolabeled as in Fig. 4. Note that TRPC2 immunoreactivity in (A) appears subcellular while that of Kv1.3 immunoreactivity (D) is localized to or compartmentalized near the membrane. The presence of RTP1 (B) or REEP1 (B-C) appears to shift some TRPC2 immunoreactivity towards the membrane while that in the presence of REEP1 (C) remains more cytosolic or intermediate. Immunoreactivity is abolished in a vector-only transfection in $\mathrm{E}\left(\mathrm{pCDNA}_{3}\right)$. Horizontal scale bar $=10 \mu \mathrm{m}$. Vertical scale bar $=50$ arbitrary units. $(A-E)=Z$-series stacked confocal image; $\left(A^{\prime}-E^{\prime}\right)=$ Representative single optical slice in the midline; $\left(A^{\prime \prime}-E^{\prime \prime}\right)=$ Intensity profiles quantified as a line scan taken at the horizontal bar in $A^{\prime}-E^{\prime}$.

transfection efficiency for each condition, respectively (Fig. 4I). TRPC2 transfection by itself (Figs. 4A and 4B) and in conjunction with either RTP1 (Figs. 4C and 4D) or REEP1 (Figs. 4E and 4F) resulted in an efficiency near 30\% (Fig. 4I). Transfection with another myc-epitope tagged six transmembrane spanning ion channel (Kv1.3) was used as a positive control (Figs. 4G-H). The TRPC2 transfection condition efficiencies were significantly below that of the positive control as measured by a one- way ANOVA followed by a Student Newman-Keuls (snk) post-hoc test $(\mathrm{F}=4.01, \mathrm{p}<0.05)$. Neither cells transfected with empty vector nor those labelled without the primary antiserum were immunoreactive (data not shown).

\section{RTP1 alters the subcellular localization of TRPC2 in vitro}

RTP1 and REEP1 are able to induce membrane expression of olfactory receptors in HEK293 [25]. Therefore, we

\section{A}

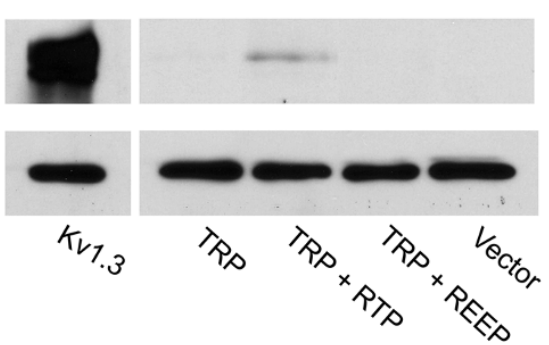

B

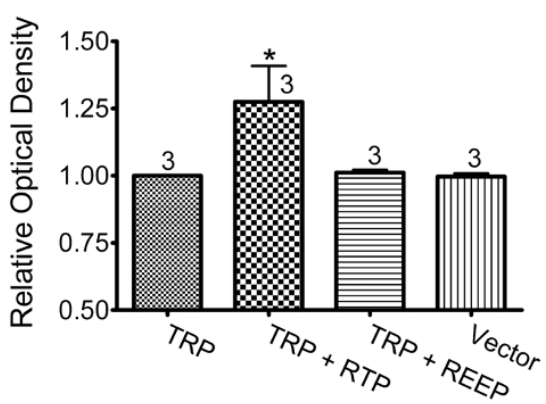

C

Transfection Condition

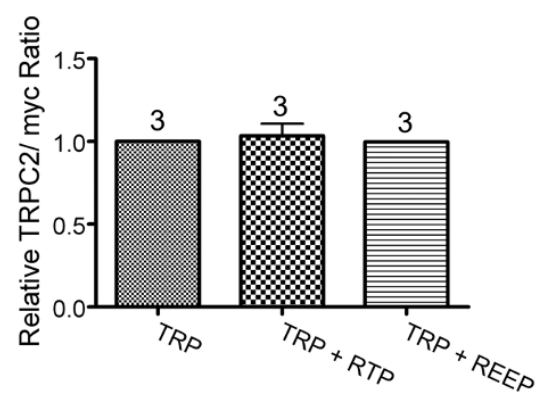

Transfection Condition

Figure 6 TRPC2 cell-surface biotinylation. Representative Western blot of TRPC2-biotinylated protein following 48 hours after transfection of indicated cDNAs in HEK293s. (A) (Top panel) Biotinylated protein products (see methods) were precipitated with streptavidin agarose beads, subjected to SDS-PAGE, and then probed with a-c-myc (1:400) to visualize myc-Kv1.3 expression (far left lane) versus that of mycTRPC2 expression under various transfection conditions. (Bottom panel) Lysate input probed with a- $\beta$-actin. (B) Histogram plot of the mean \pm s.e.m. pixel immunodensity normalized to that of the TRP alone condition. Transfection sample size noted. ${ }^{*}=$ Mean pixel density is statistically-different from channel only transfection; Dunnett's posthoc test, $p \leq 0.05$. (C) Ratio of the expression levels of mycTRPC2 and the internal standard, myc protein. Values are normalized against the channel only condition. 
sought to visualize the effect of these chaperones on the subcellular distribution of TRPC2 in the HEK293 cells. The identical transfection scheme as in Fig. 4 was repeated but high-resolution images of the labelled cells were acquired using confocal microscopy. The results of three such experiments are shown in Fig. 5. When expressed alone, TRPC2 immunoreactivity is visualized either near the nucleus (light blue; Fig. 5A) or in dense patches seemingly away from the surface membrane (bright green) and more easily viewed in an unstacked image (Fig. 5A'). In contrast, Kv1.3 immunoreactivity is visualized primarily at the surface membrane (Fig. 5D, $\left.5 D^{\prime}\right)$ and is known to insert into the surface membrane in large numbers in HEK293 cells. Interestingly, co-expression with RTP1 (Fig. 5B, 5B') results in immunoreactivity that is more typical of surface expression, with less immunoreactivity near the nucleus (ie less light blue), than that observed for the TRPC2 alone condition. Cotransfection with REEP1 results in an intermediate distribution (Fig. 5C, 5C'). Transfection of HEK293 cells with TRPC2 and both chaperones did not appear different than that of cells using transfection conditions with only one chaperone in conjunction with TRPC2 (data not shown). Cells labelled without the primary antiserum were not immunoreactive (Fig. 5E, 5E'). Line plots of each transfection condition in Fig. 5A-E demonstrate the $\alpha$ myc immunoreactivity distribution.

To biochemically confirm the suggested increase in surface expression of TRPC 2 by RTP1 and REEP1, a set of cell-surface biotinylation experiments were conducted on HEK293 cells transfected as in Fig. 5. The biotinylated surface proteins were collected and processed by SDSPAGE and visualized via Western analysis using an antiserum to the myc-epitope. Cell lysates were also processed by SDS-PAGE and visualized via Western analysis for $\beta$-actin to confirm equivalent protein loading. A representative Western blot of biotinylated TRPC2 channel is reported in Fig. 6 as quantified 48 hrs following transfection in register with subsequent functional physiological experiments below. RTP1, but not REEP1, significantly increased TRPC2 surface biotinylation (Significantly-different mean pixel density; one-way ANOVA followed by a Dunnett's post-hoc test $F=4.1, p<0.05$; Fig. 6B). When transfected alone, surface TRPC2 was detected in only 2 out of 7 trials; while when transfected with RTP1, surface TRPC 2 was detected in 7 out of 7 trials. Comparatively, myc-tagged Kv1.3 was strongly detected under either condition (Fig. 6A).

\section{Cell-surface TRPC2 is functionally detected}

To confirm that the cell-surface expressed TRPC2 was functional, a set of whole-cell electrophysiological experiments were conducted on HEK293 cells transfected as in Fig. 5. Dynabead technology using co-transfection of the channel with CD8 was employed to pan for transfected cells appropriate for whole-cell patch-clamp (see methods for details). Transfected HEK293 cells that were lightly beaded (2-4 beads) and apparently exiting mitosis were targeted in order to facilitate the generation of consistent, comparable recordings across several transfections. Cells were stimulated with a voltage-ramp protocol as described in [9] and graphically displayed in Fig. 7A. The total duration of the ramp was $140 \mathrm{~ms}$ with an interpulse interval of $60 \mathrm{~s}$. Three to five ramp pulses were applied to determine baseline current and then the recording bath was changed (see methods) to yield a final ATP concentration of $166 \mu \mathrm{M}$. Although diacylglycerol (DAG) has been reported to activate endogenous TRPC2 channels in mouse VSNs [9], in our hands neither DAG nor a synthetic analogue, OAG, was effective in gating TRPC2 current in vertebrate VSNs [14]. We therefore relied upon reported augmentation of TRPC2 via activation of purinergic current [24] as the metric of a functional assay of our in vitro system. Current at the end of the voltage-ramp protocol $(-80 \mathrm{mV})$ was used as a measure of response to ATP stimulation. As shown in Fig. 7C, cells transfected with both TRPC2 and RTP1 elicited an increase in ATP-evoked whole-cell current compared to that of control cells that were transfected, but beadless (Fig. 7A) or TRPC2-transfected only cells (Fig. 7B) (Significantly-different mean current; one-way ANOVA followed by a snk post-hoc test $\mathrm{F}=7.68, \mathrm{p}<0.05$; Fig. 7E). Additionally, a different population of heavily-beaded cells $(\mathrm{N}=7)$ were observed, which had much larger voltage-activated current amplitudes that ranged from 400 to 4400 pA $($ mean $=1550$ pA). These cells were minimally responsive to ATP (Fig. 7D, E) and were only observed in dishes transfected with both TRPC2 and RTP1.

\section{Discussion}

These experiments demonstrate that the putative olfactory receptor chaperone RTP1 interacts with not only proteins of the GPCR superfamily, but also with ion channels. This novel finding was demonstrated in vivo by a protein-protein interaction between TRPC2 and RTP1, and in vitro by a RTP1-dependent increase in TRPC2 surface expression. An ion channel complex consisting of TRPC2, Homer, and $\mathrm{IP}_{3} \mathrm{R} 3$ may exist in vivo. Our biochemical experiments indicate that TRPC2, the scaffold protein Homer $1 \mathrm{~b} / \mathrm{c}$, and the ion channel $\mathrm{IP}_{3} \mathrm{R} 3$ form protein-protein interactions in the native VNO. To the best of our knowledge, an interaction between Homer and TRPC2 has not been demonstrated in any sensory system. Lastly, our data represent the first characterization of Homer expression in the rat VNO.

Homers are widely expressed in both the male and female rat including, but not limited to, many brain regions and the testes. Although these biochemical data 


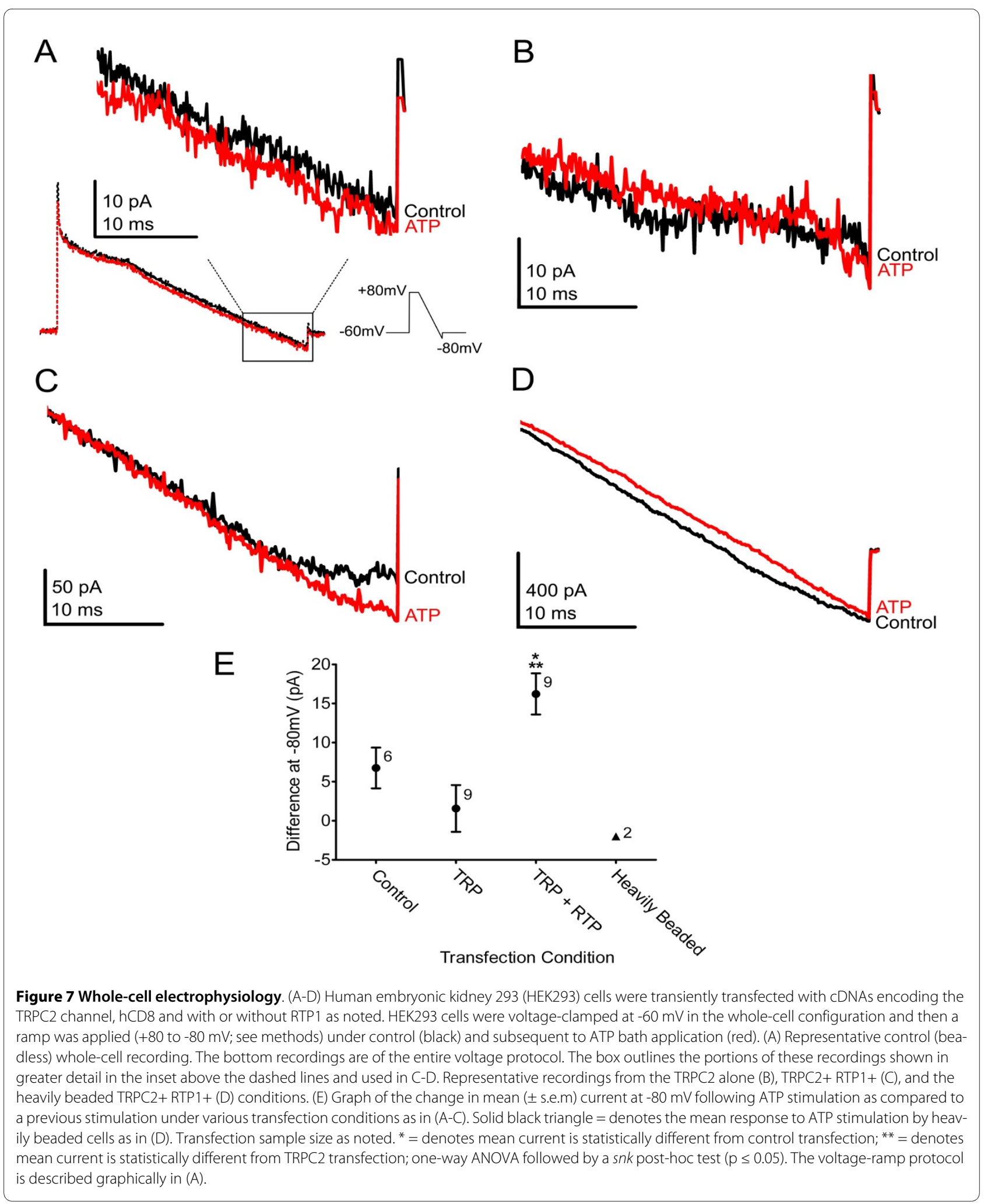

cannot exclusively rule out the possibility of Homer expression in non-sensory regions, Homers are typically associated with either post-synaptic membranes $[20,22,28-30,21,31]$ or membranes involved in calcium signalling [19]. The VNO lysates used in these experiments contained both of these subcellular elements, consistent with previous expression patterns for Homer. The non-sensory portions of the VNO are densely innervated 


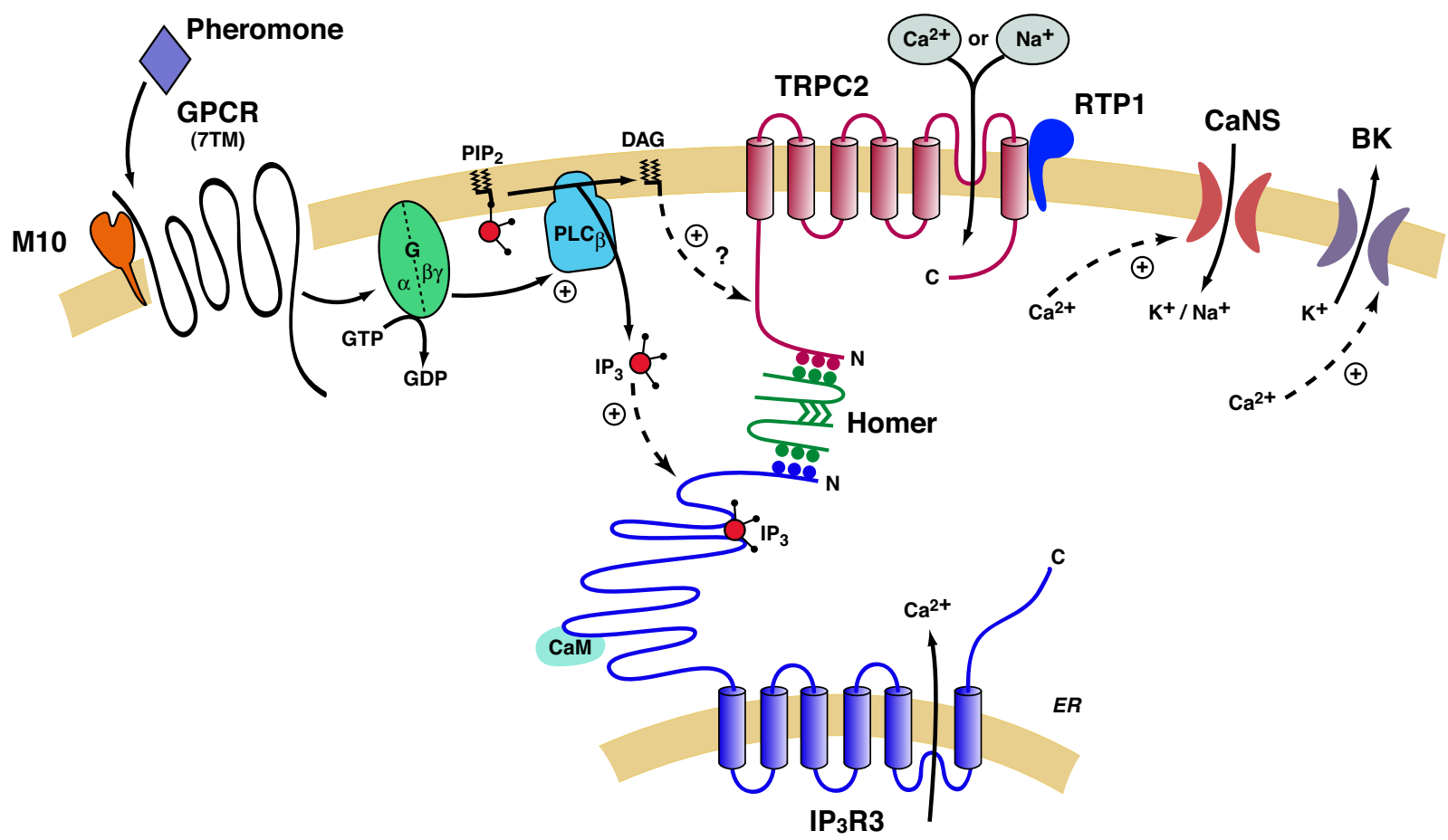

Figure 8 Schematic of the hypothetical vomeronasal organ transduction model. The vomeronasal organ (VNO) signal transduction pathway begins at either a type 1 vomeronasal (V1R) or type 2 vomeronasal (V2R) G-protein coupled receptor (GPCR); V2Rs may be associated with a member of the M10 major histocompatibility protein family. Upon pheromone binding, the V1R/V2R activates a guanidine trisphosphate-binding protein (G-protein). The activated G-protein stimulates the cleavage of phosphatidylinositol 4,5-bisphosphate $\left(\mathrm{PIP}_{2}\right)$ into 1,4,5-inositol trisphosphate $\left(\mathrm{IP}_{3}\right)$ and diacylglycerol (DAG) via phospholipase C (PLC). DAG has been reported to gate the non-specific cation current through the type 2 canonical transient receptor potential channel (TRPC2). Although binding of $I_{3}$ to the $\mathbb{I P}_{3}$ receptor $\left(\mathrm{IP}_{3} \mathrm{R}\right)$ is not supported to yield a transduction current alone, two isoforms of $I P_{3} R\left(I P_{3} R 2\right.$ and $\left.I P_{3} R 3\right)$ are expressed in the $V N O$, and $I P_{3} R 3$ forms a complex with TRPC2. Whether or not ligand occupancy is required, inhibition of complex formation blocks chemosignal-activated current. TRPC2 expression is increased in the VSN microvillar membrane with the assistance of the chaperone receptor transporting protein 1 (RTP1), whereby the channel associates with both Homer 1b/c and IP R3. A calcium activated nonselective ion channel (CaNS) can amplify the chemosignal-induced current following the rise in intracellular calcium. This rise in intracellular calcium also actives calcium-activated big conductance potassium ion channels (BK) as well as calmodulin (CaM), which may bind to both IP $\mathrm{P}_{3} \mathrm{R}$ and TRPC2.

by the autonomic nervous system [3,32] and the sensory microvilli contain a well-explored calcium-signalling pathway (Fig. 8) [1,14,18]. Homer isoforms expressed in the VNO could function similarly in smooth muscle cells and in chemosensory signal transduction. Unlike mouse data reported by [33], we do not find Homer 2 expression in the rat VNO. Overall, we detected neither a sex difference in VNO expression of Homer $1 \mathrm{~b} / \mathrm{c}$ and 3 isforms nor an appreciable amount of the Homer 2 isoform.

Our data demonstrating transcription of RTP1 and REEP1 in the rat VNO support the previous finding of these transcripts in the mouse VNO [25]. The fact that our immunocytochemical characterization supports the detection of RTP1 protein in olfactory sensory neuron cilia, VSN microvilli, goblet cells and in the soft-palate while RTP1 is not detected in the non-sensory respiratory epithelium, may provide important clues as to function. In vitro experiments support RTP1 interactions with
GPCRs associated with either odorant [25] or taste receptor families [34]. Similar protein-protein interactions have not been found, however, with VRs [25].

Alternatively, MHC class $1 \mathrm{~b}$ proteins have been found to associate with the V2Rs and thus may not function with TRPC2 [35,36]. Allowing for several different protein associations including M10-VR, RTP1-TRPC2, and Homer-TRPC2-IP 3 R3 provides the pheromone transduction cascade with multiple regulatory sites (Fig. 8).

The immunoprecipitation data indicate that Homer is not expressed in the non-sensory areas of the VNO, rather it is expressed in VSN microvilli. Other data have indicated that TRPC channels can interact with Homer proteins [16]. For example, TRP (the drosophila homologue of TRPC [37]) is involved in such interactions in the invertebrate photoreceptor [17]. Functionally, Homer expression in the VSN would allow for receptor and channel modulation. Linking TRPC2 and $\mathrm{IP}_{3} \mathrm{R} 3$ via 
Homer 1 would ensure high-fidelity transmission of the calcium signal that flows through the open TRPC2 channel during chemosignal detection. Homer 3 does not form protein-protein interactions with TRPC2 [16]. The inducible form of Homer (1a isoform) was not detected in the rat VNO. This short form lacks the coiled-coiled domain and would oppositely be predicted to disassemble a TRPC2-Homer 1-IP 3 R3 complex (see Fig. 8). Disruption of this interaction could alter TRPC2 activity in a manner similar to Homer 1a modulation of mGluR activity [21]. In previous VSN recordings, disruption of the interaction between $\mathrm{TRPC} 2$ and $\mathrm{IP}_{3} \mathrm{R} 3$ resulted in a diminished chemosignal response [14]. On the other hand, TRPC1 mutants lacking Homer binding sites formed spontaneously active channels when expressed in vitro [16] and gene-targeted deletion of Homer 1 increased TRPC1 activity in vivo [16,38]. Thus, Homer 1 could provide the VSN signalling apparatus with flexibility in responding to and adapting to chemosignals. The interaction between TRPC 2 and RTP1 could provide further regulation of TRPC2 and the response of VSNs to chemosignals, by modulation of total TRPC2 activity dependent upon surface expression driven by the chaperone. The recognition sequence for RTP1 binding will need to be investigated in future experiments.

The plasmid containing TRPC2-C14 had a low transfection efficiency in HEK293 cells. Transient transfection of a plasmid containing Kv1.3 produces an efficiency percentage of approximately 60\% [39], whereas TRPC2 efficiency is only about $30 \%$. Poor transfection efficiencies have been noted of some constructs using polycationic transfection reagents [40]; however, other researchers have tried alternative transient transfection methods with TRPC2 and reported comparably low efficiencies [23,41]. It is interesting to speculate that the low transfection efficiency might be a result of apoptosis due to calcium cytotoxicity associated with spontaneously active TRPC2 channels. At least one other TRPC channel, TRPC4, has been demonstrated to be spontaneously active in HEK293 cells [42]. In light of the facts that neither chaperone increased TRPC2 transfection efficiency nor did this efficiency match that of Kv1.3, a structurally similar channel [43], suggests that proper TRPC2 cellular distribution and function may require binding partners not present in our experiments. Lastly, RTP1 and REEP1 do not appear to be toxic to the HEK293 cells, as transfection efficiency did not decrease with their expression.

RTP1 and REEP1 appear to alter the sub-cellular distribution of TRPC2 in vitro. In HEK293 cells, TRPC2 immunolabeling is predominately in large deposits that are presumably vesicles, as imaged with laser confocal microscopy. Although every transfection condition with TRPC2 led to vesicular immunolabeling, the presence of either RTP1 or REEP1 seemed to shift expression of the channel toward the surface membrane. These data indicate a functional relationship for the RTP1-TRPC2 coimmunoprecipitation found in VNO tissue. Our data cannot distinguish the mechanism of TRPC2 surface expression, which could be the result of either increased TRPC2 inserted or inhibition of TRPC2 internalization.

Demonstration of robust Kv1.3 surface expression lends credence to the assumptions made earlier when comparing sub-cellular localization of TRPC2 in different transfection conditions. Namely, when transfected with chaperone, the TRPC2 immunolabeling signal was similar to the Kv1.3 immunolabeling in terms of subcellular distribution. A similar shift in the immunolabeling signal of olfactory receptors occurs when these receptors are expressed in vitro with RTP or REEP [25] and with unrelated GPCRs [44]. It then follows that with the addition of chaperone, more TRPC2 is in the surface membrane. In support of this notion, in each transfection condition where TRPC2 and RTP1 were transfected together, TRPC2 was detected in the surface membrane. When expressed alone, TRPC2 was infrequently detected in the surface membrane. Increased TRPC2 surface expression was detected with both cell-surface biotinylation and with whole-cell electrophysiology.

The endogenous metabotropic ATP receptor pathway utilized in our experiments to investigate in vitro TRPC2 current is similar to the VNO sensory transduction pathway as each activates PLC (Fig. 8) [24,45,46]. The electrophysiological data indicate that the surface expressed TRPC2 is functional and able to respond to a signal transduction pathway similar to that present in the VNO. That heavily-beaded, and presumably highly expressing, TRPC2+ RTP1+ cells were minimally responsive to purinergic stimulation is not unexpected. TRPC3, another TRPC channel, gains and loses agonist-induced activity based on expression level [47]. Alternatively, the TRPC2 protein level may have been high enough and the purinergic receptor protein level low enough, that any interaction between the two might be negligible due to stoichiometric limitations.

Regardless of the mechanism, these data suggest that the half-life residence of TRPC2 in the membrane is increased in the presence of RTP1. These results may indicate that the functional interaction between RTP1 and TRPC 2 is one of membrane stabilization rather than trafficking. This is a different functional role for RTP1 from previously described [25] and is speculative. With both olfactory and gustatory GPCRs, RTP1 is presumed to traffic its target to the surface membrane [25,34].

Based upon our current results in the context of current knowledge $[1,48,49]$, we propose the following model (Fig. 8). A chemosignal binds to either VR-type GPCR, activation of which ultimately results in a TRPC2dependent calcium influx across the surface membrane. 
Calcium can also enter the cytosol from the endoplasmic reticulum via $\mathrm{IP}_{3} \mathrm{R} 3$. Homer 1 binding at either TRPC2 terminus [50] (residues 303PPTLL and 953LPVPF) may alter the channel function. TRPC2 and mGluRs are both integral transmembrane proteins and, therefore, the known interactions of $\mathrm{mGluR} / \mathrm{IP}_{3} \mathrm{R}$ [28] could be replaced by TRPC2/IP ${ }_{3} \mathrm{R}$ complex formation in the VNO. For example, Homer 1 may cluster $\mathrm{IP}_{3} \mathrm{R} 3$ to TRPC2 using Homer binding motifs (PPXF, PPXXF and LPSSP) on both channels in a similar fashion that Homers cluster $\mathrm{IP}_{3} \mathrm{R} 3$ to mGluR [51]. This would be advantageous for at least two reasons. First, the products of phospholipase $\mathrm{C}$ hydrolysis of $\mathrm{PIP}_{2}, \mathrm{IP}_{3}$ and DAG, gate both $\mathrm{IP}_{3} \mathrm{R} 3$ and TRPC2. Maintaining close proximity of the second-messenger targets would increase the speed of the signalling cascade and decrease the amount of second-messenger lost due to errant diffusion. Second, as $\mathrm{IP}_{3} \mathrm{R} 3$ may adopt a conformation that favors opening upon calcium binding [52], tethering $\mathrm{IP}_{3} \mathrm{R} 3$ next to the calcium source would increase the speed of the signalling cascade. By tethering $\mathrm{IP}_{3} \mathrm{R} 3$ underneath TRPC2, Homer would be expected to increase the open probability of $\mathrm{IP}_{3} \mathrm{R} 3$ using calcium influx contributed through the surface channel TRPC2. Thus, Homer could both increase the speed and the efficiency of the TRPC2 signalling cascade as it does for mGluR cascades. Signal adaptation is likely to come from calcium-calmodulin inhibition of both $\mathrm{IP}_{3} \mathrm{R} 3$ [53] and TRPC2 [54], calcium-activated big conductance potassium channels (BK) $[55,56]$ and metabolism of DAG into the lipid arachidonic acid [56,57].

Although complexes of channels and adaptors have been found in the visual system, Homer is a relatively newly discovered protein, and appears to be involved in scaffolding, targeting, and localization. Our previous finding of a direct protein-protein interaction between $\mathrm{IP}_{3} \mathrm{R} 3$ and TRPC2 in the VNO neither ruled out an additional role for scaffolding proteins, such as the Homer family, nor a role for chaperones, such as REEP1 and RTP1. In fact, the addition of chaperones and the formation of an adaptor complex may be critical to channel function and eagerly warrants future experimentation.

\section{Conclusions}

The VNO expresses members of the Homer protein family. TRPC2 complexes with both $\mathrm{IP}_{3} \mathrm{R} 3$ and Homer1b/c in vivo in the VNO. RTP1 is expressed in the VNO, co-localizes with other members of the VNO transduction pathway and may be a member of the transduction pathway as it forms a protein-protein interaction with TRPC2 in vivo. In vitro, RTP1 appears to function as a chaperone of TRPC2, increasing the amount of functional channel in the surface membrane.

\section{Methods}

\section{Animal care and maintenance}

Postnatal Day 30 (P30) Sprague-Dawley rats were used for biochemistry experiments and were housed on a 12 $\mathrm{h}: 12 \mathrm{~h}$ light:dark cycle in the Florida State University (FSU) vivarium. All procedures were performed in accordance with the FSU Animal Care and Use Committee and $\mathrm{NIH}$-approved guidelines.

\section{Solutions}

Solutions used for protein sample or tissue preparation, including phosphate buffered saline (PBS), lysis buffer (LB), wash buffer (WB), and protease and phosphatase inhibitor solution (PPI), were made as described in [58]. Tissue extract buffer (TEB) was prepared as in [22]. Cellsurface biotinylation solutions, including biotinylation lysis buffer and biotinylation quench buffer, were made as described by [59]. Immunoblot stripping buffers, including tris stripping buffer (TSB) and sodium citrate stripping buffer (SCSB), were also made as described in Colley et. al. (2007). Electrophysiology solutions were prepared as in [24] and were as follows (in $\mathrm{mM}$ ): intracellular pipette $150 \mathrm{KCl}, 10 \mathrm{HEPES} \mathrm{pH}$ 7.2, $2 \mathrm{MgCl}_{2}, 10$ glucose; extracellular bath $140 \mathrm{NaCl}_{2}, 10 \mathrm{HEPES} \mathrm{pH} 7.4,4 \mathrm{KCl}, 4$ $\mathrm{CaCl}_{2}, 1 \mathrm{MgCl}_{2}$, and 10 glucose. All chemicals were obtained from either Sigma Chemical Company (St. Louis, MO, USA) or Fisher Scientific (Suwanne, GA, USA).

\section{Plasmids and antibodies}

All encoded cDNAs were downstream from a cytomegalovirus (CMV) promoter. TRPC2 clone 14, with an N-terminal myc-epitope (EQKLISEEDL), was prepared in the $\mathrm{pcDNA}_{3}$ vector and was a kind gift from Dr. L Birnbaumer (National Institute of Environmental Health Sciences) [10]. RTP1 and REEP1 were in the $\mathrm{pCI}$ vector and were kind gifts of Dr. H. Matsunami (Duke University) [25]. pCDM8 was a kind gift from Dr. Brian Seed (Harvard University) [60]. DNA encoding human CD8 was amplified from pCDM8 and subcloned into the pcDNA vector (Carlsbad, CA, Invitrogen) between the BamH1 and EcoR1 restriction sites. cDNA encoding Kv1.3 was subcloned into the $\mathrm{pcDNA}_{3}$ vector (Carlsbad, CA, Invitrogen) at the unique HindIII restriction site within the multiple cloning region [39]. Kv1.3 was also epitopetagged via insertion of the myc sequence on the extracellular face of the channel between the S1 and S2 transmembrane domains [58].

$\mathrm{T} 1 \mathrm{NH}, \mathrm{T} 2 \mathrm{NH}$, and T3NH are anti-peptide polyclonal antibodies specific for the type-1, -2 and $-3 \mathrm{IP}_{3} \mathrm{R}$ isoforms, respectively, and were raised against the following amino terminal sequences (amino acid position in parentheses): $\mathrm{T} 1 \mathrm{NH}=$ CLATGHYLAAEVDPDQEVDPDQ- 
DASR (308-326), T2NH = CPDYRDAQNEGKTVRDGKTVRDGELP (320-338) and T3NH = CENPSYKGDVSDPGDVSDPKAAGPGA (319-337). These antibodies were a generous gift of Dr Gregory Mignery (Loyola University Chicago, Stritch College of Medicine, Maywood, IL, USA) [61]. An antiserum detecting TRPC2 as raised in guinea pig and directed against the $\mathrm{N}$-terminal cytosolic domain CSSDASGAGPGGPLRNVE was a generous gift of Dr. Richard Axel (Columbia University, New York, NY, USA) [12]. Anti-peptide polyclonal antibodies detecting the different forms of Homer were made by immunizing rabbits with the synthetic C-terminal peptides of Homer 1b/c (IFELTELRDNLAKLLECS), 2a/b (GKIDDLHDFRRGLSKLGTDN), or 3 (RLFELSELRE-GLARLAEAA) conjugated to thyroglobulin with glutaraldehyde [22]. A fourth, rabbit polyclonal antiserum recognizing all Homer 1 (1a, 1b, and 1c) isoforms was generated against the full-length GST-Homer 1a fusion protein [20]. These antibodies were a generous gift of Dr. Paul Worley (Johns Hopkins University, Baltimore, MD, USA). A polyclonal antibody recognizing all Homer proteins (Pan-Homer; 1a, 1b, 1c, 2a, 2b, 3) was made by immunizing rats with recombinant Homer 1a (AB5875, Chemicon/Millipore, St. Louis, MO, USA). The mouse monoclonal antiserum for the c-myc epitope was from Roche (Indianapolis, IN, USA). Rabbit polyclonal antiserum specific to RTP1 was a kind gift of Dr. Hiro Matsunami (Duke University, Durham, NC, USA) [62]. When necessary to validate equal protein loading, a rabbit polyclonal antibody detecting cellular actin was used. The immunogen for this antibody was SGPSIVHRKCF attached to a Multiple Antigen Peptide (MAP) backbone (Sigma Chemical).

\section{Tissue homogenization and Western blotting}

Tissue extracts were prepared as in [22]. Briefly, P30 rats were killed by $\mathrm{CO}_{2}$ inhalation, decapitated, and VNOs were rapidly dissected and placed in ice cold TEB with PPI. Samples on ice were sonicated (Sonic Dismembrator, Model 60, Fisher Scientific) twice for eight seconds on setting number five. Non-soluble matter was removed by ultracentrifugation (Beckman Coulter, Fullerton, CA, USA) at $37,000 \times g$ for $30 \mathrm{~min}$ at $4^{\circ} \mathrm{C}$. The supernatant was aliquoted and stored at $-80^{\circ} \mathrm{C}$ until use. The resultant pellet was solubilized in $2 \%$ sodium dodecyl sulfate (SDS), aliquoted, and stored at $-80^{\circ} \mathrm{C}$ in case the initial screening of the lysates did not yield membrane-associated fractions.

Immunoprecipitations were performed as in [18]. In brief, P30 rat VNOs were homogenized with a size 20 Kontes glass tissue-homogenizer (Kontes Glass, Vineland, NJ, USA) on ice in LB with PPI. Lysis was continued on a Roto-Torque (Model 7637, Cole-Parmer Instruments, Vernon Hills, IL, USA) for $30 \mathrm{~min}$ at $4{ }^{\circ} \mathrm{C}$. Lysates were clarified by centrifugation at $15,000 \times \mathrm{g}$
(Eppendorf, Model 5415C, Westbury, NY, USA) for 10 min at $4^{\circ} \mathrm{C}$ and then precleared for 1 hour (hr) with $3 \mathrm{mg} /$ $\mathrm{ml}$ protein A sepharose (GE Healthcare, Uppsalla). This was followed by another centrifugation step to remove the protein A sepharose. Proteins of interest (Homer 1b/ c, Homer 2, Homer 3, TRPC2, IP 3 R3, RTP1) were immunoprecipitated from the clarified lysates by overnight incubation on a Roto-Torque at $4^{\circ} \mathrm{C}$ with $5 \mu \mathrm{g} / \mathrm{ml}$ of appropriate antiserum. Samples were then incubated for $3 \mathrm{hr}$ with protein A sepharose and centrifuged as above. Immunoprecipitates were washed four times with 5 volumes of WB. Lysates and washed immunoprecipitates were diluted in SDS gel loading buffer containing [63] 1 $\mathrm{mM} \mathrm{Na} \mathrm{VO}_{4}$ and stored at $-20^{\circ} \mathrm{C}$ until use.

Purified VNO tissue extracts or immunoprecipitated proteins were separated on 6 to 15\% acrylamide gels by SDS-PAGE and electro-transferred to nitrocellulose membranes. Equal protein loading $(30 \mu \mathrm{g})$ was controlled by Bradford protein assay (BioRad, Hercules, CA, USA) and confirmed by $0.1 \%$ Fast Green staining and $\alpha$ - $\beta$-actin labeling. The nitrocellulose membrane was blocked with $5 \%$ non-fat milk for $60 \mathrm{~min}$, incubated overnight at $4{ }^{\circ} \mathrm{C}$ in primary antisera against TRPC2 (1:2000), $\mathrm{IP}_{3} \mathrm{R}_{3}(1: 2000)$, RTP1 (1:1000), Homer 1b/c (1:1000), Homer 2a/b (1:2000), Homer 3 (1:2000), Homer 1 isoforms (Worley, 1:1000), all Homer isoforms (Chemicon, 1:1000), or RTP1 (1:1000). Membranes were then incubated with horseradish peroxidase-conjugated species-specific secondary antibody (donkey anti-rabbit, Amersham Biosciences or rabbit anti-guinea pig, Sigma) for $90 \mathrm{~min}$ at room temperature (rt). Labelled protein was detected with enhanced chemiluminescence (ECL; Amersham Biosciences, Piscataway, NJ, USA) using Classic Blue autoradiography film BX (MidSci, St. Louis, MO, USA). To ensure equal loading, nitrocellulose membranes were stripped by incubating blots in eight ten-minute washes of TSB, followed by eight ten-minute washes of SCSB, then re-probed using $\alpha-\beta$-actin (1:1000). Autoradiographs were scanned using a Hewlett-Packard Photosmart Scanner (Model 106-816; Hewlett-Packard, San Diego, CA, USA) and quantified by line scanning densitometry using Quantiscan Software (Biosoft, Cambridge, UK).

\section{RNA extraction and reverse-transcriptase PCR}

P30 rats were killed by $\mathrm{CO}_{2}$ inhalation, decapitated, and VNOs were rapidly dissected from the surrounding tissues and placed on dry ice. RNA was extracted using the SV Total RNA Isolation System as per the manufacturer's protocol (Promega, Madison, WI, USA). RNA purity and concentration was determined by UV spectroscopy (NanoDrop-1000, Wilmington, DE, USA). cDNA was reversetranscribed using the ImPromII kit as per manufacturer's protocol (Promega). Gene-specific primers have been previously reported [34] and were as follows: 
RTP1_forward, AAGCGTGACCACAGATGAGTG; RT P1_reverse, GAGCAGAAGTTCCAGCCTGAG; REEP1_ forward, CAATGAATTCCCACCATGGTGTCATGGA TCATCTCCAGGC; REEP1_reverse, GACTAGCGGCCGCCTAGGCGGTGCCTGAGCTGCTAG. PCR products were resolved using 1.0\% agarose gel electrophoresis and visualized via UV excitation of the incorporated ethidium bromide.

\section{Human embryonic kidney cell (HEK293) maintenance and transfection}

HEK 293 cells were maintained in minimum essential medium (MEM), 2\% penicillin/streptomycin, and $10 \%$ FBS (Gibco BRL). Before transfection, cells were grown to confluence ( $\sim 7$ days), dissociated with trypsin, and replated to low density onto Corning substrate-coated plasticware on poly-d-lysine-treated glass coverslips as previously described [39]. HEK293 cells were transfected for 4-5 hrs at $37^{\circ} \mathrm{C}$ with plasmid cDNA and LipofectamineTM transfection reagent (Invitrogen, Carlsbad, CA, USA) in OptiMEM serum-reduced media (Gibco BRL). Either $1.5 \mu \mathrm{g}$ of plasmid DNA and $7.5 \mu \mathrm{l}$ Lipofectamine were applied to $30-50 \%$ confluent glass coverslips in $35 \mathrm{~mm}$ dishes or $3.0 \mu \mathrm{g}$ of plasmid DNA and $15 \mu \mathrm{l}$ Lipofectamine were applied to $80-95 \%$ confluent $60 \mathrm{~mm}$ dishes, for immunocytochemical and biochemical experiments, respectively. $\mathrm{pcDNA}_{3}$ vector was used to normalize total DNA concentration in co-transfection conditions, as previously [64].

\section{Immunocytochemistry}

Thirty-six hrs post-transfection, HEK293 cells were washed in PBS and fixed in ice-cold St. Marie's fixative (1.0\% acetic acid in $95 \%$ ethanol). Cells were washed three times in PBS and incubated for $30 \mathrm{~min}$ at $\mathrm{rt}$ in PBSTblock $(0.1 \%$ Triton $\mathrm{x}-100$ in PBS and $1 \%$ Bovine Serum Albumin). Cells were immunolabeled with primary antisera diluted in PBST-block for $90 \mathrm{~min}$ at rt or overnight at $4^{\circ} \mathrm{C}$ with $\alpha$-c-myc. Cells were then washed three times in PBS. The secondary antisera were applied at rt for $1.5 \mathrm{hr}$ in PBS using fluorescein isothiocyanate-conjugated goat anti-mouse antiserum (1:200). Following three washes in PBS, cells were counter-stained with a five-minute incubation in diamidino-phenyindole (DAPI) in PBS (1:5000). The cells were mounted on glass slides with Vectashield (Vector Laboratories, Burlingame, CA, USA) to prevent photobleaching.

Tissue sections $(\sim 16 \mu \mathrm{m})$ were prepared from P30 rats that had been fixed-perfused (4\% paraformaldehyde) and sucrose cryoprotected as previously described [18]. Sections were air-dried on the bench for 60 minutes, rehydrated with $\mathrm{PBS}$, and then incubated at $80^{\circ} \mathrm{C}$ in $10 \mathrm{mM}$ sodium citrate for 30 minutes for antigen retrieval [65]. The sections were cooled and non-specific binding was blocked by a 60-minute incubation in blocking solution (5\% normal goat serum $/ 2.5 \% \mathrm{BSA} / 0.3 \%$ triton in $\mathrm{PBS}$ ). During the block, the primary antibodies were treated with L-glutathione to cap reactive $\mathrm{SH}$-functional groups. On ice, an L-glutathione/Tris-EDTA solution was diluted in the blocking solution containing the primary antiserum to a final concentration of $30 \mathrm{mM}$ L-glutathione Tris-EDTA/1.25\% normal goat serum/0.625\% BSA/ $0.075 \%$ triton [66]. After the block, sections were rinsed with Tris-EDTA - $0.3 \%$ triton and incubated with antiserum overnight in a darkened, humidified chamber. Antiserum for RTP1 was used at a final dilution of 1:200 and antisera for TRPC2 was used at 1:400. Sections to be stained using the $\mathrm{ABC}$ method were treated according to the manufacturer's protocol (Vector, Burlingham, CA, USA) and the precipitate was visualized with the chromagen AEC (Sigma). Immunofluorescence was detected with either donkey anti-rabbit Texas Red (Amersham Biosciences) or rabbit anti-guinea pig FITC (Sigma).

\section{Microscopy}

Conventional light microscopy was performed on an Axiovert S-100 (Zeiss, Thornwood, NY, USA) equipped with epifluoresence, an AxioCam camera (\#412-312, Zeiss), and Axiovision data capture software (version 3.1, Zeiss). Images were captured with a pixel resolution of $1300 \times 1030$. Laser confocal microscopy was performed on an Axioplan 2 microscope attached to an LSM510 two-confocal system (Zeiss). FITC was excited at 488 and DAPI at $700 \mathrm{~nm}$ with argon/2 and titanium/sapphire lasers, respectively. Images were captured at $1024 \times 1024$ pixels resolution in LSM file format, and then were converted to a 16-bit TIFF file format using LsMB software (Zeiss). The TIFF file was opened in NIH ImageJ http:// rsb.info.nih.gov/ij/ and a uniform rectangle of 200 pixels $\times 20$ pixels was applied across the center of the cell $(\mathrm{Z}$ axis) to obtain the plot density profile of the pixels underneath, as previously described [67].

\section{Transfection efficiency analysis}

Three to nine fields of view for each transfection condition (TRPC2 + pcDNA 3 , TRPC2 + RTP1, TRPC2 + REEP1, and Kv1.3 + pcDNA 3 ) were captured under a fluorescent and either a brightfield or a DAPI emission. Each field of view was approximately $90,000 \mu \mathrm{m}^{2}$. Transfection efficiency was calculated for each field of view as the ratio of the number of fluorescent cells divided by the total number of cells. Cell counts were performed using NIH ImageJ software.

\section{Cell-surface biotinylation}

Cell-surface biotinylation was performed as described [59]. Briefly, either 24- or 48-hr post-transfection, HEK293 cells were washed with ice-cold PBS and then 
incubated with $1.0 \mathrm{mg} / \mathrm{ml}$ biotin (Pierce, Rockford, Ill, USA) in PBS for $30 \mathrm{~min}$ at $4^{\circ} \mathrm{C}$. Following a PBS rinse, cells were incubated for $30 \mathrm{~min}$ at $4^{\circ} \mathrm{C}$ in quench buffer, rinsed again, and then lysed for $30 \mathrm{~min}$ at $4^{\circ} \mathrm{C}$ in lysis buffer. Lysed cells were scraped, triturated, and centrifuged at $12,000 \mathrm{rpm}$ for $10 \mathrm{~min}$ at $4^{\circ} \mathrm{C}$. The supernatants were collected and aliquots were set aside for confluency controls. Protein concentration was calculated using a Bradford assay (BioRad). Equal amounts of protein were brought up to $1 \mathrm{ml}$ with PBS (pH 8.0) and incubated overnight at $4^{\circ} \mathrm{C}$ with $40 \mu \mathrm{l}$ streptavidin-conjugated agarosebeads (Pierce). The beads were pelleted with a centrifugation of $12,000 \mathrm{rpm}$ for $10 \mathrm{~min}$ at $4^{\circ} \mathrm{C}$, washed, and then stored at $-20^{\circ} \mathrm{C}$ until further use.

\section{Whole-cell electrophysiology}

Hoffman modulation contrast optics was used to visualize cells at 40× magnification (Axiovert 135, Carl Zeiss). Thirty-six hrs post-transfection, HEK293 cells were rinsed with bath solution and incubated with anti-hCD8 beads (Dyna-Beads, Invitrogen) to mark transfected cells (either hCD8+/TRPC2+/RTP1- or cCD8+/TRPC2+/ RTP1+) [60]. Co-expression with CD8 allows visualization of cells taking up the cDNA encoding the channel or receptor of interest by marking transfected cells with a red polypropylene-antibody-linked bead. We [64] and others [58] have demonstrated that single cells take up multiple constructs equivalently and that the density of the beads is proportional to the expression of channel of interest. Cells were rinsed two times before beginning a recording session to remove any unbound beads. Cells were rinsed two more times before beginning a recording session. Electrophysiological records were analyzed using software from Microcal Origin (Northampton, MA) and Quattro Pro (Borland International, Scotts Valley, CA).

Patch electrodes were fabricated from Jencons glass (Jencons Limited, Bridgeville, PA) with pipette resistances between 9 and $14 \mathrm{M} \Omega$. Macroscopic currents were recorded in the whole-cell configuration using an Axopatch-200B amplifier (MDS Analytical Technologies/ Axon Instruments, Sunnyvale, CA), filtered at $5 \mathrm{kHz}$, digitized at $5 \mathrm{kHz}$, and stored for later analysis. All voltage signals were generated and data were acquired with the use of an Axon Digidata 1200 board with pClamp v9.2 software (Axon Instruments). Cells were held routinely at a holding potential $\left(\mathrm{V}_{\mathrm{h}}\right)$ of $-60 \mathrm{mV}$, stepped to $80 \mathrm{mV}\left(\mathrm{V}_{\mathrm{c}}\right)$, held for 40 milliseconds (ms), and then changed to a ramp protocol by falling to $-80 \mathrm{mV}$ over $100 \mathrm{~ms}(-1.6 \mathrm{mV} /$ $\mathrm{ms})$. The total pulse duration was $140 \mathrm{~ms}$ and the inter pulse interval was 60 seconds. Several sweeps were taken over the 3-6 minutes after establishing the whole-cell configuration to establish a stable baseline. ATP stimulation was achieved with bath application of $0.5 \mathrm{ml}$ of 500 $\mu \mathrm{M}$ for a final bath concentration of $\sim 166 \mathrm{mM}$ ATP. Peak inward current amplitude was measured at $-80 \mathrm{mV}$ from a subsequent sweep.

\section{Data analysis}

Numerical data were statistically analyzed using Prizm software (version 4, GraphPad, San Diego, CA, USA). One-way Analysis of Variance (ANOVA) with either a Student-Newman-Keuls (snk) or a Dunnett's post-hoc test was performed with statistical significance determined at the $95 \%$ confidence interval.

\section{Additional material}

\begin{abstract}
Additional file 1 Fig. S1 - RTP1 Antiserum Characterization and Immunoprecipitation Controls. (A) NP40-solubilized samples of mouse main olfactory epithelia (MOE), collected at noted postnatal (P) stages, were separated by SDS-PAGE and electro-transferred to nitrocellulose. RTP1 antiserum recognized the appropriate band (expected $\mathrm{Mr}=25 \mathrm{kDa}$ ). The faint band at the arrowhead may be an RTP1 variant described previously in the MOE [62], but not observed in the VNO (Fig. 3). The top blot probed for the RTP1 chaperone (RTP1) was stripped and reprobed for $\beta$-actin (Actin)(Mr = $42 \mathrm{kDa}$ ). (B-C) HEK293 cells transfected with the RTP1 expression vector were incubated at $37^{\circ}$ with either (B) PBS or (C) $200 \mu \mathrm{g} / \mu \mathrm{l}$ proteinase K. Cells were immunolabelled with aRTP1 without detergent and processed for RTP1 immunoreactivity as described previously [68]. Note the loss of RTP1 immunoreactivity in (C). (D) VNO lysates were used in immunoprecipitation experiments as in Fig. 3, except non-immune rabbit sera was used as the source of the first immunoglobulin. Note the loss of bands at the expected $M_{r}$ for TRPC2 97, IP $R 3$ > 220, Homer 1b/c 45, and RTP1 25 kDa as indicated. $\lg \mathrm{G}=$ the heavy chain of the immunoglobin $\mathrm{G}$
\end{abstract}

\section{Authors' contributions}

TGM carried out the experiments employing immunocytochemistry, electrophysiology, biotinylation, and RT-PCR. Both TGM and JHB conducted the immunoprecipitation and SDS-PAGE/Western experiments. DAF directed the performed research. All authors conceived the experiments, evaluated the design of controls, and wrote sections of the manuscript. All authors read and approved the final manuscript.

\section{Acknowledgements}

The authors would like to thank Dr. Richard Axel for donation of TRPC2 antisera, Dr. Gregory Mignery for donation of $\mathrm{IP}_{3} \mathrm{R} 3$ antisera and antigenic peptide, Dr. Hiro Matsunami for donation of RTP1 antiserum, and Drs. Paul Worley and Joseph Yuan for donation of Homer antisera and valuable assistance concerning methodology of tissue extracts. We would like to thank Dr. James M. Fadool and Ms. Kimberly Riddle for imaging assistance and Mr. Andre Irsigler for cloning assistance through the Department of Biological Science. We would like to thank Mr. Robert Daly, Mr. Jeffery Godbey, and Mr. Michael Henderson for routine technical assistance and mouse colony maintenance. We would also like to thank Mr. Charles Badland for excellent graphic design assistance and Dr. Patricio Velez for reading a previous version of the manuscript. This work was supported by two training grant mechanisms at the National Institutes of Health (NIH), T32 DC00044 and F31 DC006153 specifically through the National Institutes of Deafness and Communication Disorders (NIDCD).

\section{Author Details}

'Department of Biological Science, The Florida State University, Tallahassee, FL, 32306, USA, 2Program in Neuroscience, The Florida State University,

Tallahassee, FL, 32306 USA, 3 Institute of Molecular Biophysics, King Life Science Building, Tallahassee, FL, 32306, USA and ${ }^{4}$ Current Address: Columbia University, 914 Fairchild, MC 2439, 1212 Amsterdam Ave., New York, NY 10027

Received: 11 October 2009 Accepted: 21 May 2010 Published: 21 May 2010 


\section{References}

1. Halpern M, Martinez-Marcos A: Structure and function of the vomeronasal system: an update. Progress in Neurobiology 2003 70:245-318.

2. Meredith M, Marques DM, O'Connell RO, Stern FL: Vomeronasal pump: significance for male hamster sexual behavior. Science 1980, 207:1224-1226

3. Meredith $M, O^{\prime}$ Connell RJ: Efferent control of stimulus access to the hamster vomeronasal organ. J Physiol 1979, 286:301-316.

4. Vaccarezza OL, Sepich LN, Tramezzani JH: The Vomeronasal organ of the rat. Journal of Anatomy 1981, 132:167-185

5. Dulac C, Axel R: A novel family of genes encoding putative pheromone receptors in mammals. Cell 1995, 83:195-206.

6. Matsunami H, Buck L: A Multigene Family Encoding a Diverse Array of Putative Pheromone Receptors in Mammals. Cell 1997, 90:775-784.

7. Ryba NJP, Tirindelli R: A New Multigene Family of Putative Pheromone Receptors. Neuron 1997, 19:371-379.

8. Liman ER, Corey DP, Dulac C: TRP2: A candidate transduction channel for mammalian pheromone sensory signaling. Proceedings of the National Academy of Sciences 1999, 96:5791-5796.

9. Lucas P, Ukhanov K, Leinders-Zufall T, Zufall F: A Diacylglycerol-Gated Cation Channel in Vomeronasal Neuron Dendrites Is Impaired in TRPC2 Mutant Mice: Mechanism of Pheromone Transduction. Neuron 2003, 40:551-561.

10. Vannier B, Peyton M, Boulay G, Brown D, Qin N, Jiang M, Zhu X, Birnbaumer L: Mouse trp2, the homologue of the human trpc2 pseudogene, encodes mTrp2, a store depletion-activated capacitative $\mathrm{Ca} 2+$ entry channel. Proceedings of the National Academy of Sciences 1999, 96:2060-2064

11. Kimchi $T, X u J$, Dulac $C$ : A functional circuit underlying male sexual behaviour in the female mouse brain. Nature 2007, 448:1009-1014

12. Leypold BG, Yu CR, Leinders-Zufall T, Kim MM, Zufall F, Axel R: Altered sexual and social behaviors in trp2 mutant mice. Proceedings of the National Academy of Sciences 2002, 99:6376-6381.

13. Stowers L, Holy TE, Meister M, Dulac C, Koentges G: Loss of Sex Discrimination and Male-Male Aggression in Mice Deficient for TRP2. Science 2002, 295:1493-1500.

14. Brann JH, Fadool DA: Vomeronasal sensory neurons from Sternotherus odoratus (stinkpot/musk turtle) respond to chemosignals via the phospholipase C system. J Exp Biol 2006, 209:1914-1927.

15. Kim JY, Zeng W, Kiselyov K, Yuan JP, Dehoff MH, Mikoshiba K, Worley PF, Muallem S: Homer 1 Mediates Store- and Inositol 1,4,5-Trisphosphate Receptor-dependent Translocation and Retrieval of TRPC3 to the Plasma Membrane. J Biol Chem 2006, 281:32540-32549.

16. Yuan JP, Kiselyov K, Shin DM, Chen J, Shcheynikov N, Kang SH, Dehoff MH, Schwarz MK, Seeburg PH, Muallem S, et al:: Homer Binds TRPC Family Channels and Is Required for Gating of TRPC1 by IP3 Receptors. Cell 2003, 114:777-789.

17. Huber A: Scaffolding proteins organize multimolecular protein complexes for sensory signal transduction. European Journal of Neuroscience 2001, 14:769-776.

18. Brann JH, Dennis JC, Morrison EE, Fadool DA: Type-specific inositol 1,4,5trisphosphate receptor localization in the vomeronasal organ and its interaction with a transient receptor potential channel, TRPC2. Journal of Neurochemistry 2002, 83:1452-1460.

19. Worley PF, Zeng W, Huang G, Kim JY, Shin DM, Kim MS, Yuan JP, Kiselyov K, Muallem S: Homer proteins in Ca2+ signaling by excitable and nonexcitable cells. Cell Calcium 2007, 42:363-371.

20. Brakeman PR, Lanahan AA, O'Brien R, Roche K, Barnes CA, Huganir RL, Worley PF: Homer: a protein that selectively binds metabotropic glutamate receptors. Nature 1997, 386:284-288.

21. Kammermeier PJ, Worley PF: Homer 1a uncouples metabotropic glutamate receptor 5 from postsynaptic effectors. Proceedings of the National Academy of Sciences 2007, 104:6055-6060.

22. Xiao B, Tu JC, Petralia RS, Yuan JP, Doan A, Breder CD, Ruggiero A, Lanahan AA, Wenthold RJ, Worley PF: Homer Regulates the Association of Group 1 Metabotropic Glutamate Receptors with Multivalent Complexes of Homer-Related, Synaptic Proteins. Neuron 1998, 21:707-716.

23. Hofmann T, Schaefer M, Schultz G, Gudermann T: Cloning, expression and subcellular localization of two novel splice variants of mouse transient receptor potential channel 2. Biochem / 2000, 351:115-122.
24. Jungnickel MK, Marrero H, Birnbaumer L, Lemos JR, Florman HM: Trp2 regulates entry of $\mathrm{Ca} 2+$ into mouse sperm triggered by egg ZP3. Nat Cell Biol 2001, 3:499-502

25. Saito H, Kubota M, Roberts RW, Chi Q, Matsunami H: RTP Family Members Induce Functional Expression of Mammalian Odorant Receptors. Cell 2004, 119:679-691.

26. Fadool DA, Wachowiak M, Brann JH: Patch-clamp analysis of voltageactivated and chemically activated currents in the vomeronasal organ of Sternotherus odoratus (stinkpot/musk turtle). J Exp Biol 2001, 204:4199-4212.

27. Murphy FA, Tucker T, Fadool DA: Sexual dimorphism and developmental expression of signal-transduction machinery in the vomeronasal organ. Journal of Comparative Neurology 2001, 432:61-74

28. Tu JC, Xiao B, Naisbitt S, Yuan JP, Petralia RS, Brakeman P, Doan A, Aakalu VK, Lanahan AA, Sheng M, et al:: Coupling of mGluR/Homer and PSD-95 Complexes by the Shank Family of Postsynaptic Density Proteins. Neuron 1999, 23:583-592.

29. Kaja S, Yang SH, Wei J, Fujitani K, Liu R, Brun-Zinkernagel AM, Simpkins JW, Inokuchi K, Koulen P: Estrogen Protects the Inner Retina from Apoptosis and Ischemia-Induced Loss of Vesl-1L/Homer 1c Immunoreactive Synaptic Connections. Invest Ophthalmol Vis Sci 2003, 44:3155-3162.

30. Gasperini R, Foa L: Homer 1b/c expression correlates with zebrafish olfactory system development. Journal of Neurocytology 2004 33:671-680.

31. Lu J, Helton TD, Blanpied TA, Racz B, Newpher TM, Weinberg RJ, Ehlers MD: Postsynaptic Positioning of Endocytic Zones and AMPA Receptor Cycling by Physical Coupling of Dynamin-3 to Homer. Neuron 2007 55:874-889.

32. Soler MVC, Suburo AM: Innervation of blood vessels in the vomeronasal complex of the rat. Brain Research 1998, 811:47-56.

33. Shiraishi Y, Mizutani A, Yuasa S, Mikoshiba K, Furuichi T: Differential expression of Homer family proteins in the developing mouse brain. The Journal of Comparative Neurology 2004, 473:582-599.

34. Behrens M, Bartelt J, Reichling C, Winnig M, Kuhn C, Meyerhof W: Members of RTP and REEP Gene Families Influence Functional Bitter Taste Receptor Expression. J Biol Chem 2006, 281:20650-20659.

35. Loconto J, Papes F, Chang E, Stowers L, Jones EP, Takada T, Kumanovics A, Lindahl KF, Dulac C: Functional Expression of Murine V2R Pheromone Receptors Involves Selective Association with the M10 and M1 Families of MHC Class Ib Molecules. Cell 2003, 112:607-618.

36. Olson R, Huey-Tubman KE, Dulac C, Bjorkman PJ: Structure of a Pheromone Receptor-Associated MHC Molecule with an Open and Empty Groove. PLoS Biol 2005, 3:e257.

37. Venkatachalam K, Montell C: TRP Channels. Annual Review of Biochemistry 2007, 76:387-417.

38. Stiber JA, Zhang ZS, Burch J, Eu JP, Zhang S, Truskey GA, Seth M, Yamaguchi N, Meissner G, Shah R, Worley PF, Williams RS, Rosenberg PB: Mice Lacking Homer 1 Exhibit a Skeletal Myopathy Characterized by Abnormal TRP Channel Activity. Mol Cell Biol 2008, 28:2637-2647.

39. Fadool DA, Holmes TC, Berman K, Dagan D, Levitan IB: Tyrosine Phosphorylation Modulates Current Amplitude and Kinetics of a Neuronal Voltage-Gated Potassium Channel. J Neurophysiol 1997 78:1563-1573.

40. Yamamoto M, Okumura S, Schwencke C, Sadoshima J, Ishikawa Y: High efficiency gene transfer by multiple transfection protocol. The Histochemical Journal 1999, 31:241-243.

41. Hofmann T, Schaefer M, Schultz G, Gudermann T: Subunit composition of mammalian transient receptor potential channels in living cells. Proceedings of the National Academy of Sciences 2002, 99:7461-7466.

42. McKay RR, Szymeczek-Seay CL, Lievremont JP, Bird GS, Zitt C, Jüngling E, Lückhoff A, Putney JW: Cloning and expression of the human transient receptor potential 4 (TRP4) gene: localization and functional expression of human TRP4 and TRP3. Biochem J 2000, 351:735-746.

43. Lepage PK, Boulay G: Molecular determinants of TRP channel assembly. Biochemical Society Transactions 2007, 035:81-83.

44. Bush CF, Jones SV, Lyle AN, Minneman KP, Ressler KJ, Hall RA: Specificity of Olfactory Receptor Interactions with Other G Protein-coupled Receptors. J Biol Chem 2007, 282:19042-19051.

45. Schachter JB, Sromek SM, Nicholas RA, Harden TK: HEK293 human embryonic kidney cells endogenously express the P2Y1 and P2Y2 receptors. Neuropharmacology 1997, 36:1181-1187. 
46. Van Kolen K, Slegers H: Integration of P2Y receptor-activated signal transduction pathways in $\mathrm{G}$ protein-dependent signalling networks. Purinergic Signalling 2006, 2:451-469.

47. Vazquez G, Wedel BJ, Trebak M, John Bird G, Putney JW Jr: Expression Level of the Canonical Transient Receptor Potential 3 (TRPC3) Channel Determines Its Mechanism of Activation. J Biol Chem 2003, 278:21649-21654

48. Zufall F, Ukhanov K, Lucas P, Leinders-Zufall T: Neurobiology of TRPC2: from gene to behavior. Pflügers Archiv European Journal of Physiology 2005, 451:61-71

49. Tirindelli R, Dibattista M, Pifferi S, Menini A: From Pheromones to Behavior. Physio/ Rev 2009, 89:921-956.

50. Stamboulian S, Moutin MJ, Treves S, Pochon N, Grunwald D, Zorzato F, De Waard M, Ronjat M, Arnoult C: Junctate, an inositol 1,4,5-triphosphate receptor associated protein, is present in rodent sperm and binds TRPC2 and TRPC 5 but not TRPC1 channels. Developmental Biology 2005, 286:326-337.

51. Worley PF, Zeng W, Huang GN, Yuan JP, Kim JY, Lee MG, Muallem S: TRPC channels as STIM1-regulated store-operated channels. Cell Calcium 2007, 42:205-211.

52. Hamada K, Terauchi A, Mikoshiba K: Three-dimensional Rearrangements within Inositol 1,4,5-Trisphosphate Receptor by Calcium. J Biol Chem 2003, 278:52881-52889.

53. Taylor CW, Laude AJ: IP3 receptors and their regulation by calmodulin and cytosolic Ca2+. Cell Calcium 1911, 32:321-334.

54. Spehr J, Hagendorf S, Weiss J, Spehr M, Leinders-Zufall T, Zufall F: Ca2+Calmodulin Feedback Mediates Sensory Adaptation and Inhibits Pheromone-Sensitive lon Channels in the Vomeronasal Organ. J Neurosci 2009, 29:2125-2135.

55. Ukhanov K, Leinders-Zufall T, Zufall F: Patch-Clamp Analysis of GeneTargeted Vomeronasal Neurons Expressing a Defined V1r or V2r Receptor: lonic Mechanisms Underlying Persistent Firing. $J$ Neurophysiol 2007, 98:2357-2369.

56. Zhang P, Yang C, Delay RJ: Urine stimulation activates BK channels in mouse vomeronasal neurons. J Neurophysiol 2008:90555.

57. Spehr M, Hatt $\mathrm{H}$, Wetzel CH: Arachidonic Acid Plays a Role in Rat Vomeronasal Signal Transduction. J Neurosci 2002, 22:8429-8437.

58. Colley BS, Biju KC, Visegrady A, Campbell S, Fadool DA: Neurotrophin B receptor kinase increases Kv subfamily member 1.3 (Kv1.3) ion channel half-life and surface expression. Neuroscience 2007, 144:531-546.

59. Fu Y, Subramanya A, Rozansky D, Cohen DM: WNK kinases influence TRPV4 channel function and localization. Am J Physiol Renal Physiol 2006, 290:F1305-F1314.

60. Jurman ME, Boland LM, Liu Y, Yellen G: Visual identification of individual transfected cells for electrophysiology using antibody-coated beads. Biotechniques 1994, 17:876-881.

61. Ramos-Franco J, Caenepeel S, Fill M, Mignery G: Single Channel Function of Recombinant Type-1 Inositol 1,4,5-Trisphosphate Receptor Ligand Binding Domain Splice Variants. Biophysical Journal 1998, 75:2783-2793.

62. Zhuang $\mathrm{H}$, Matsunami $\mathrm{H}$ : Synergism of Accessory Factors in Functional Expression of Mammalian Odorant Receptors. J Biol Chem 2007 282:15284-15293

63. Sambrook J, Fitsch E, Maniatis T: Molecular Cloning: A Laboratory Manual Cold Spring Harbor: Cold Spring Harbor Press; 1989.

64. Cook KK, Fadool DA: Two Adaptor Proteins Differentially Modulate the Phosphorylation and Biophysics of Kv1.3 Ion Channel by Src Kinase. Biol Chem 2002, 277:13268-13280.

65. Jiao Y, Sun Z, Lee T, Fusco FR, Kimble TD, Meade CA, Cuthbertson S, Reiner A: A simple and sensitive antigen retrieval method for free-floating and slide-mounted tissue sections. Journal of Neuroscience Methods 1999 93:149-162

66. Rogers AB, Cormier KS, Fox JG: Thiol-reactive compounds prevent nonspecific antibody binding in immunohistochemistry. Lab Invest 2006, 86:526-533

67. Marks DR, Fadool DA: Post-synaptic density perturbs insulin-induced Kv1.3 channel modulation via a clustering mechanism involving the SH3 domain. Journal of Neurochemistry 2007, 103:1608-1627.

68. Manganas LN, Trimmer JS: Subunit Composition Determines Kv1 Potassium Channel Surface Expression. J Biol Chem 2000, 275:29685-29693. doi: 10.1186/1471-2202-11-61

Cite this article as: Mast et al., The TRPC2 channel forms protein-protein interactions with Homer and RTP in the rat vomeronasal organ BMC Neuroscience 2010, 11:61

\section{Submit your next manuscript to BioMed Central and take full advantage of:}

- Convenient online submission

- Thorough peer review

- No space constraints or color figure charges

- Immediate publication on acceptance

- Inclusion in PubMed, CAS, Scopus and Google Scholar

- Research which is freely available for redistribution
C Biomed Central 